\title{
Lavandula angustifolia
}

National Cancer Institute

\section{Source}

National Cancer Institute. Lavandula angustifolia. NCI Thesaurus. Code C101763.

A plant with aromatic leaves and flowers that is a member of the mint family. Oil from the flowers has been used in some cultures to treat certain medical problems, to keep insects away, and to wash in. It is also used in aromatherapy. Perillyl alcohol, a substance found in lavender, is being studied in cancer prevention and treatment. 